Dyslexic children have an auditory processing disorder, sometimes associated with an altered perception of voicing and MOC dysfunction that may be reversed following audiovisual training. (Veuillet E, Magnan A, Ecalle J, Thai-Van H, Collet L. Auditory processing disorder in children with reading disabilities: effect of audiovisual training. Brain November 2007;130:2915-2928). (Respond: Dr Evelyne Veuillet, Hopital Edouard Herriot, Pavilion U Service d'Audiologie et d'Explorations Orofaciales, Place d'Arsonval, 69437 Lyon Cedex 03, France).

E-mail: evelyne.veuillet@chu-lyon.fr

COMMENT. Auditory system processing may be impaired in some dyslexics, and audiovisual training is an effective method of remediation. (Magnan A et al. Dyslexia 2004:10:1-10). A sensory temporal processing deficit impairs the ability to relate word sounds and letter sounds and to associate the printed letter (grapheme) with the appropriate speech sound (phoneme). Most dyslexics have deficient phonological awareness and difficulty converting graphemes to phonemes. Researchers at the Univ of Florida, Gainesville, suggest that deficits in motor-articulatory programming or feedback are the basis for developmental dyslexia (Heilman KM et al. Ann Neurol 1996;39:407-412) (Ped Neur Briefs April 1996). A disconnection syndrome hypothesis is proposed based on PET studies conducted at the MRC Cognitive Development Unit, London, UK (Paulesu E et al. Brain 1996;119:143-157). Brain regions normally activated in phonological processing (left inferior frontal lobe, temporo-parietal and subcortical regions) are defective, leading to weak connections between anterior and posterior language areas. Background noise, frequently found in a classroom, aggravates impairment of cortical encoding of phonemes in learning disabled children. (King C et al. Neurosci Lett 2002;319:111-115, cited by author). The medial olivocochlear (MOC) system is probably involved in speech intelligibility-in-noise, a system that functions more strongly in musicians and may become more resistant to noise with auditory training. (Hayes EA et al. Clin Neurophysiol 2003;114:673-684). A link to some examples of voiced voiceless cognate words: http www.speech-languagetherapv.com tx-loiceless-1 s-voiced-2.pdf These include Paul ball/ pig big/ pat bat/ pin bin/ (from Caroline Brown), provided courtesy of Denise Boggs MS-CCC/SLP, Speech, Language and Swallowing Services, Children's Memorial Hospital, Chicago.

\title{
SLEEP EEG IN BOYS WITH ATTENTION DEFICIT DISORDER
}

Researchers at the University of Montreal, Canada, studied spectral analysis of nonREM sleep (stages 2, 3 and 4 ) and REM sleep EEG in 6 boys (age 10.3+/- 1.2) with ADHD compared to 6 healthy controls. None had comorbidities, and none had received methylphenidate for at least 48 hours. Compared to controls, ADHD boys had less slowwave activity (SWA;0.75-2.25 Hz) in frontal and parietal regions. The findings point to an impairment of the thalamo-frontocortical loop in ADHD. (Gingras MA, Labrosse M, Chevrier E et al. Spectral analysis of Non-REM and REM sleep EEG in boys with attentiondeficit/hyperactivity disorder. Abstracts of presentations at the $4^{\text {th }}$ Annual Joint Meeting of the EEG and Clinical Neuroscience Society (ECNS) and the International Society for Neuroimaging in Psychiatry (ISNIP) in Montreal, Quebec, Canada, September 19-23, 2007. 
Clinical EEG and Neuroscience October 2007;38:216-217). (Respond: E-mail: Marc-Andre Gingras: masleep(ahotmail.com)

COMMENT. Previous studies of the waking EEG in ADHD children by the above authors had found abnormalities in frontal, temporal, parietal and occipital regions. Researchers from the Universities of Wollongong and Sydney, Australia, report that increased delta and theta in frontal regions in unmedicated girls with ADHD was normalized by treatment with methylphenidate. Stimulant medication in ADHD girls may improve processing deficits rather than increasing arousal levels. (Clarke A, Barry R, McCarthy R et al. Effects of stimulant medications on the EEG of girls with attention-deficit/hyperactivity disorder. Abstracts of presentations at the $16^{\text {th }}$ Annual Conference of the Australian Society for Psychophysiology December 9-11, 2006, Canberra, Australia. Clinical EEG and Neuroscience Oct 2007;38:222). (Respond: E-mail: Adam Clarke: aclarke(@uow.edu.au).

Epileptiform activity in the EEG is reported with varying frequency from $7 \%$ to $30 \%$ of children with ADHD (Hughes JR et al. Epilepsy \& Behavior 2000;1:271-277; Ped Neur Briefs Oct 2000;14:73-74). Methylphenidate treatment of ADHD complicated by centrotemporal rolandic spikes in the EEG has a risk of precipitating seizures in $16.7 \%$ compared to only $0.6 \%$ in patients with normal EEGs. (Hemmer SA et al. Pediatr Neurol 2001;24:99-102; Ped Neur Briefs July 2007;21:49-50). For a comprehenive review of ADHD and epilepsy comorbidity, see Schubert R 2005, in Ped Neur Briefs 2005;19:1-2.

\section{VASCULAR DISORDERS}

\section{IRON-DEFICIENCY ANEMIA AND STROKE}

The prevalence of iron-deficiency anemia (IDA) in young children at the time of stroke and in age-matched healthy controls was compared in a case-control study conducted at the Hospital for Sick Children, Toronto, Canada. IDA was significantly more common among case patients $(8(53 \%)$ of 15$)$ than control subjects $(13(9 \%)$ of 143$)$. Patients and controls were aged 12 to 38 months; median ages of 24 vs 21 months were not significantly different. Case patients had a lower median hemoglobin level and mean corpuscular volume and a higher median platelet count than controls. Patients with IDA had serum ferritin levels below $12 \mathrm{mcg} / \mathrm{L}$. Three stroke cases without IDA had varicella infection and prior prothrombotic risk factors. Six stroke cases (4 with IDA) had acute otitis media, pneumonia, or acute gastroenteritis infections. Stroke patients were 10 times more likely to have IDA than healthy children without stroke. More than half of all stroke cases in otherwise healthy children had IDA as a risk factor. Stroke due to sinovenous thrombosis was more closely associated with IDA than arterial ischemic stroke. (Maguire JL, de Veber G, Parkin PC. Pediatrics 2007;120:1053-1057). (Respond: Patricia C Parkin MD, Division of Pediatric Medicine, Hospital for Sick Children, 555 University Ave, Toronto, Ontario, Canada M5G 1X8).

COMMENT. IDA is a significant risk factor for vasoocclusive stroke in otherwise healthy children. In a series of 212 children with a first ischemic stroke, reported from Great Ormond Street Hospital, London, a previous medical diagnosis was identified in 